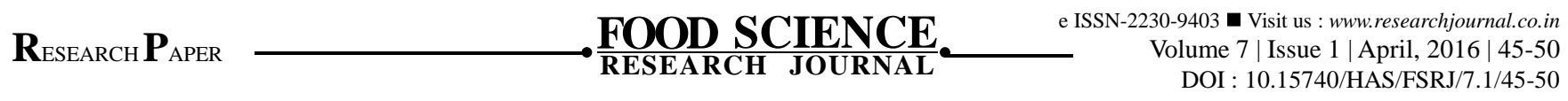

\title{
Assessment of dietary intake of pre-school children (4-6 years) belonging to slum areas of Ludhiana
}

\author{
Navjot Kaur, Priya Singla and NeerJa Singla
}

\begin{abstract}
Micronutrient deficiencies in the early part of life may lead to severe health hazards in the later life. Unawareness regarding nutrition, poverty, ignorance and illiteracy in the slum areas leads to less intake of nutrients than recommended and aggravates the health problems to great extent. A study group belonging to low socio economic status residing in slum areas aged (4-6 years) was selected for their daily food and nutrient intake. General information, family history, dietary habits, food and nutrient intake was obtained using a questionnaire. Macronutrient intake of the subjects portrayed a surplus intake of protein and fat in comparison to RDA but micronutrient deficient intakes of the study group was seen. Intake of energy, $\beta$-carotene, thiamine, riboflavin, niacin, folic acid, ascorbic acid, iron, calcium and zinc was less than recommended intake. Less intake of nutrients were observed to be due to the less average food intake of all the food groups among the subjects.
\end{abstract}

Key Words : Food intake, Nutrient intake, Pre-school children, Slum areas

How to cite this article : Kaur, Navjot, Singla, Priya and Singla, Neerja (2016). Assessment of dietary intake of pre-school children (4-6 years) belonging to slum areas of Ludhiana. Food Sci. Res. J., 7(1): 45-50. 